\title{
Non-destructive Dissolution Testing Correlation
}

\author{
Kuny T.,2 Schatz C., 1 Ulmschneider M., 1 Marrer S., 1,2 Leuenberger H.,2 \\ IPharmaceutical Quality Assurance and Quality Control, F. Hoffmann-La Roche Ltd, Basel, Switzerland \\ 2 Institute of Pharmaceutical Technology, University of Basel, Switzerland
}

email:tanja.kuny@unibas.ch caspar.schatz@roche.com

\section{Abstract}

To replace conventional laborious dissolution testing of immediate-release tablet formulations by nondestructive near-infrared (NIR) transmission spectroscopy, single and model-dependent dissolution parameters were examined to determine whether they yielded results similar to those of the primary method. The non homogeneous dissolution process made the dissolution models unsuitable for establishing calibrations. The best calibration was found using a single parameter: percent active substance dissolved after $20 \mathrm{~min}(\% 20 \mathrm{~min})$. Accuracy $-99.8 \%$ recovery - was in the same range as that of the primary method $(100.4 \%)$ in which dissolution was monitored by fiber optics directly in the dissolution vessel;precision, on the other hand, was poorer [relative standard deviations: $1.13 \%$ (calibration set) and $3.70 \%$ (validation set) vs $0.75 \%]$. This study strongly suggests that non-destructive dissolution analysis using NIR transmission spectroscopy can be used in dissolution testing.

\section{Introduction}

$\mathrm{N}$ on-destructive analysis using near infrared (NIR) spectroscopy is increasingly popular, especially for routine identification tests [14] and content determinations. The elimination of laborious sample preparation increases throughput. Application has therefore been investigated to other routine analyses $[5,6]$,e.g. content uniformity $[7,8]$, coating thickness and quality [9$11]$, and hardness testing of solid formulations [1216].The present study tested the feasability of NIR spectroscopy for determining particle size, crystallinity, hardness and coating characteristics, all of which are key parameters in the dissolution of solid formulations.

In the NIR range $\left(0.8-2.5 \mu \mathrm{m}, 12,500-4,000 \mathrm{~cm}^{-1}\right.$ respectively), overtones and combinations of the vibration of $\mathrm{CH}, \mathrm{OH}$ and $\mathrm{NH}$ bonds are mainly observed. Excitation is relatively low, enabling thick samples such as tablets to be penetrated.The NIR signal measured is a complex function of physical and chemical parameters that has to be resolved chemometrically [17].

A single sample parameter is normally correlated with the sample NIR spectrum in chemometry, meaning that the whole dissolution process has to be reduced to one value. This can be achieved using single points on the dissolution profile,e.g.the dissolution half-life $\left(t_{50 \%}\right)$ or percent active substance dissolved after $20 \mathrm{~min}\left(\%_{20 \mathrm{~min}}\right)$, or by using the dissolution pretreatments available in special dissolution models [18-20] (Table 1).

\section{Experimental}

Figure 1, page 23, illustrates the study design.

\section{Samples}

The feasibility study was conducted on immediaterelease benzodiazepine tablets $(\mathrm{N}=81)$ containing $6 \mathrm{mg}$ active substance (Table 2).

40 tablets were assigned to the calibration set, 20 to 


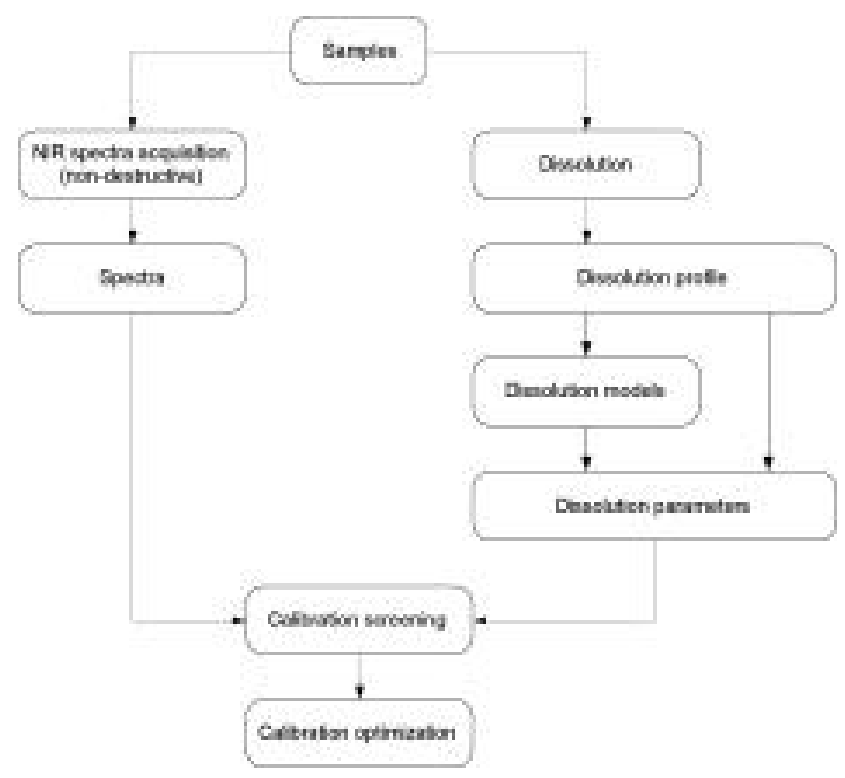

Figure 1: Experimental Study Design
974725/18, Hellma GmbH \& Co.,Müllheim/Baden, Germany) and a scanning spectrometer (Varian Cary 50,Varian International AG, Zug, Switzerland) directly in the vessel [23]. The wavelength of $239 \mathrm{~nm}$ at the peak maximum $\left(\mathrm{A}_{239}\right)$ was used to quantify the amount of dissolved substance, with subtraction of excipient interference at the correction wavelength of $450 \mathrm{~nm}\left(\mathrm{~A}_{450}\right)$ [24].The proportion of dissolved active substance $(\%$ dissolved $)$ was quantified using two standard solutions representing $100 \%$ dissolution. Using the averaged value of the two standard concentrations $\left(\left\langle c_{\text {standard }}\right\rangle\right)$ and their weight-corrected absorption readings at $\left.239 \mathrm{~nm}\left(<A_{\text {standard }}\right\rangle\right)$, single-point calibration was performed with 15,000 as the conversion factor (Formula 1).

\section{Formula 1}

$$
\%_{\text {dissolved }}=\left(A_{239}-A_{450}\right) *\left\langle c_{\text {standard }}>* 15,000 /<A_{\text {standard }}>\right.
$$

For quality assurance reasons the difference between the weight-corrected standard absorption readings could not exceed $2.00 \%$.

Tablet dissolution was monitored for $30 \mathrm{~min}$ at a stirring rate of $50 \mathrm{rpm}$ [22], followed by an infinity test at $150 \mathrm{rpm}$ for $5 \mathrm{~min}$ to measure the total amount of active substance.
Table 2. Feasibility study samples.

\begin{tabular}{|lcl|}
\hline Samples & $\begin{array}{c}\text { Tablets/lots } \\
(\mathrm{n} / \mathrm{n})\end{array}$ & \\
\hline Regular & $51 / 17$ & room temperature, humidity uncontrolled \\
\hline Stability & $15 / 5$ & $25^{\circ} \mathrm{C}, 60 \%$ relative humidity, stored $2-5$ years \\
\hline Stability & $15 / 5$ & $30^{\circ} \mathrm{C}, 75 \%$ relative humidity, stored $2-5$ years \\
\hline
\end{tabular}

the validation set, and the remaining 21 to the challenge set as a further test of calibration. All assignments were randomized.

\section{NIR spectra acquisition}

After optimization of instrument parameters (NIRTAB 5021, Büchi Labortechnik AG, Flawil, Switzerland), transmission spectra were acquired with 10 scans against $1 \mathrm{~mm}$ Spectralon references (Büchi) in the spectral range $6000-11,520 \mathrm{~cm}^{-1}$ using tablets placed in the $5 \mathrm{~mm}$ diameter flexible sample plate (Büchi).

\section{Dissolution}

The tablets were dissolved in apparatus 2 [21] in $900 \mathrm{ml}$ pepsin-free simulated gastric fluid [21] at $37.0 \pm 0.5^{\circ} \mathrm{C}$ [22]. The extent of dissolution was measured with a fiber optic immersion probe (Ultra Mini TS $10 \mathrm{~mm}+2$ LL UV Li/SMA
Quantification measurements were acquired every 30 seconds with an averaging time of 1 second throughout the process.

The parameters $t_{50} \%$ and $\%_{20 \text { min }}$ were recorded and the mean dissolution time (MDT) calculated without including the infinity test period. The resulting profiles $(0-30 \mathrm{~min})$ were also transformed using the Rosin-RammlerSperling-Bennet-Weibull (RRSBW),Hixson Crowell,Higuchi, and biexponential kinetic models.

\section{Calibration screening and optimization}

Calibration screening was performed using the chemometric software (Nircal 3.01, Büchi) and the dissolution parameters $\mathrm{t}_{50 \%}$ and $\%_{20 \text { min, }}$ MDT, and model-dependent parameters (Table 3) REF.

Calibration was optimized using partial least square (PLS) regression and fitted with a maximum of 8 factors. Spectra were pretreated by closure-based normalization methods.

\section{Results \\ NIR data}

The NIR transmission spectra showed clear differences in absorption properties between the stability and regular samples (Figure 2, page 24). 


\section{Non-destructive Dissolution Testing Correlation ... continued}

Table 3 Model-dependent parameters used in calibration screening.

\begin{tabular}{|c|c|c|}
\hline Model & \multicolumn{2}{|c|}{ Parameters } \\
\hline $\begin{array}{l}\text { RRSBW } \\
\text { biexponential } \\
\text { Hixson Crowe } \\
\text { Higuchi }\end{array}$ & $\begin{array}{l}\mathrm{a} / \\
\mathrm{A}_{0} \\
\mathrm{k}_{\mathrm{HC}} \\
\mathrm{k}_{\mathrm{H}}\end{array}$ & $\begin{array}{l}\mathrm{b} / \mathrm{T}_{\mathrm{D}} \\
/ \mathrm{B}_{0} / \mathrm{k}_{\mathrm{a}} / \mathrm{k}_{\mathrm{b}} \\
\mathrm{c} / \mathrm{Tc}\end{array}$ \\
\hline Legend & $\begin{array}{l}a \\
b \\
A_{0} \\
B_{0} \\
k_{a} \\
k_{b} \\
k_{H} \\
k_{H C} \\
\text { RRSBW } \\
T_{C} \\
T_{D}\end{array}$ & $\begin{array}{l}\text { scaling parameter } \\
\text { shape parameter } \\
\text { amount of active substance (process 1) } \\
\text { amount of active substance (process 2) } \\
\text { dissolving constant (process 1) } \\
\text { dissolving constant (process 2) } \\
\text { dissolving constant (Higuchi model) } \\
\text { dissolving constant (Hixson Crowell model) } \\
\text { Rosin-Rammler-Sperling-Bennet-Weibull } \\
\text { critical time at which first particles of active substance disappear } \\
\text { time to } 63.2 \% \text { dissolution }\end{array}$ \\
\hline
\end{tabular}

with the stability and regular samples almost forming three different clusters reflecting the impact of the storage conditions on the formulation characteristics. These changes could also be seen in the NIR spectra (Figure 2) and dissolution behavior.

The coefficients of correlation were 0.8279 and 0.8379 for the calibration and validation sets, respectively. The so-called $Q$ value [17] (between 0 and 1, with values between 0.9 and 1 indicating very good calibration) was 0.8046 . Accuracy was $99.8 \%$ and consistency, at 98.6 , close to the ideal of 100 . Precision (RSD) was $1.13 \%$ and $3.70 \%$ for the calibration and validation sets, respectively. Quality was demonstrated by the fact that inclusion of the

\section{Dissolution data}

The mean all-tablet dissolution profile (Figure 3) showed great variation over $30 \mathrm{~min}$. The small error bars at the end of the infinity test ( 30 to $35 \mathrm{~min}$ ) indicate a constant amount of active substance in each tablet (uniformity of content).

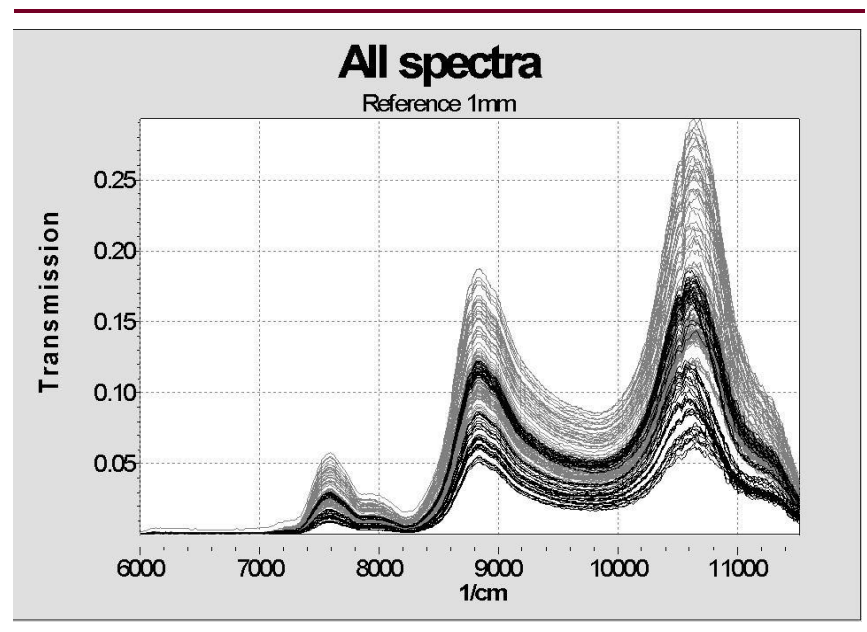

Figure 2 NIR tablet spectra [ $N=81$ : regular (grey), $n=51$; stability (black), $n=30]$.

\section{Calibration screening}

Best results were achieved using $\%_{20 \mathrm{~min}}$. Dissolution halflife $\left(t_{50 \%}\right)$ values were too similar in all tablets for calibrations to be possible [mean: $2.3 \mathrm{~min}$; relative standard deviation (RSD):0.8\%].MDT values were better distributed but did not produce good calibrations, while those obtained with all the model-dependent parameters were poorer still.

\section{Calibration optimization}

The $\%_{20 \text { min }}$ parameter (Figure 4) gave the best calibration,

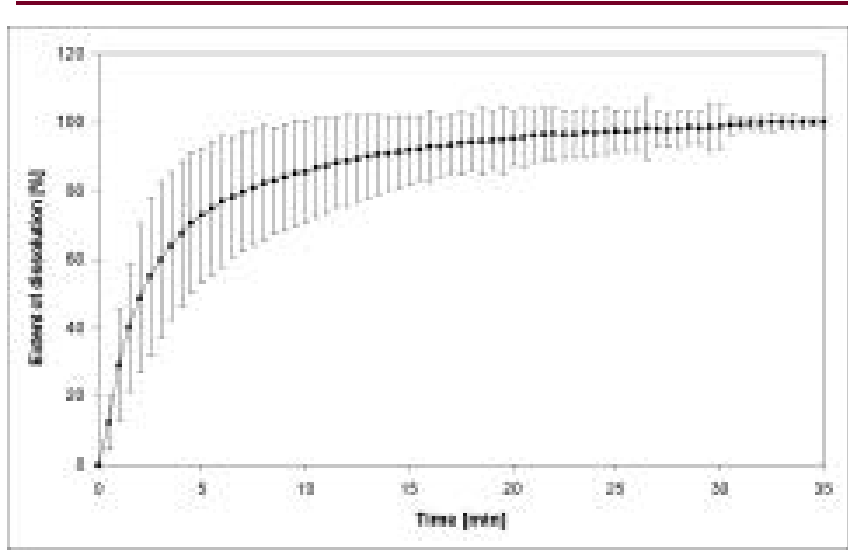

Figure 3 Mean dissolution profile in all tablets $(N=81)$. Error bars: \pm 2 standard deviations.

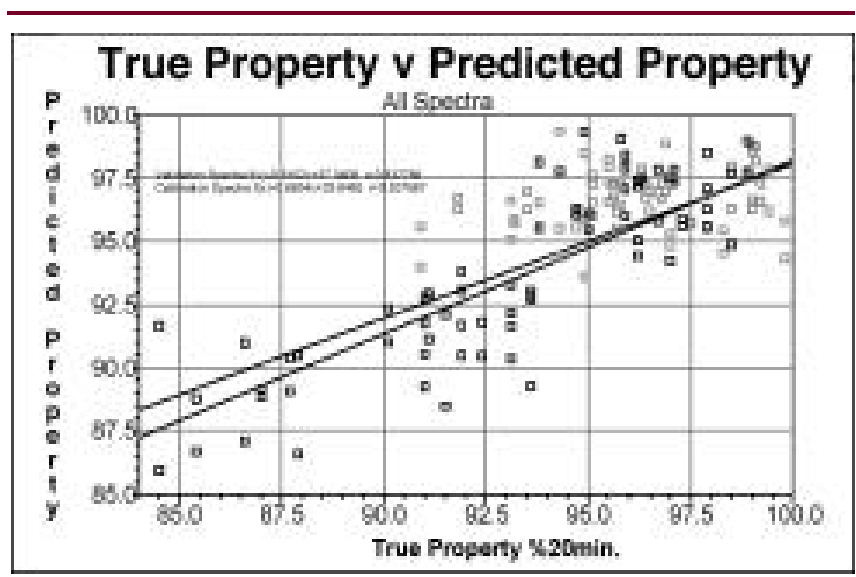

Figure 4 Optimized calibration using the $\%_{20 \min }$ parameter (black $=$ sta bility samples;grey = regular samples). 


\section{Non-destructive Dissolution Testing Correlation ... continued}

control set in the optimized calibration changed the calibration parameters only slightly. Accuracy was $99.6 \%$, consistency 106.2 and precision (RSD) $1.10 \%$ and $3.58 \%$ for the control and validation sets, respectively.

Since the NIR results are based on the primary dissolution test method, they had to be compared with the $100.4 \%$ accuracy and $0.75 \%$ precision (RSD) of the latter. The residuals (true property - predicted property) were plotted against their true properties (Figure 5). The maximal residual was $-7.15 \%$ and the graphic suggests a slight trend towards an exponential line.

\section{Discussion and conclusions}

This feasibility study has proved that the dissolution of immediate-release tablets can be correlated with the NIR spectra.

The number of scans chosen for the spectra - 10 - was

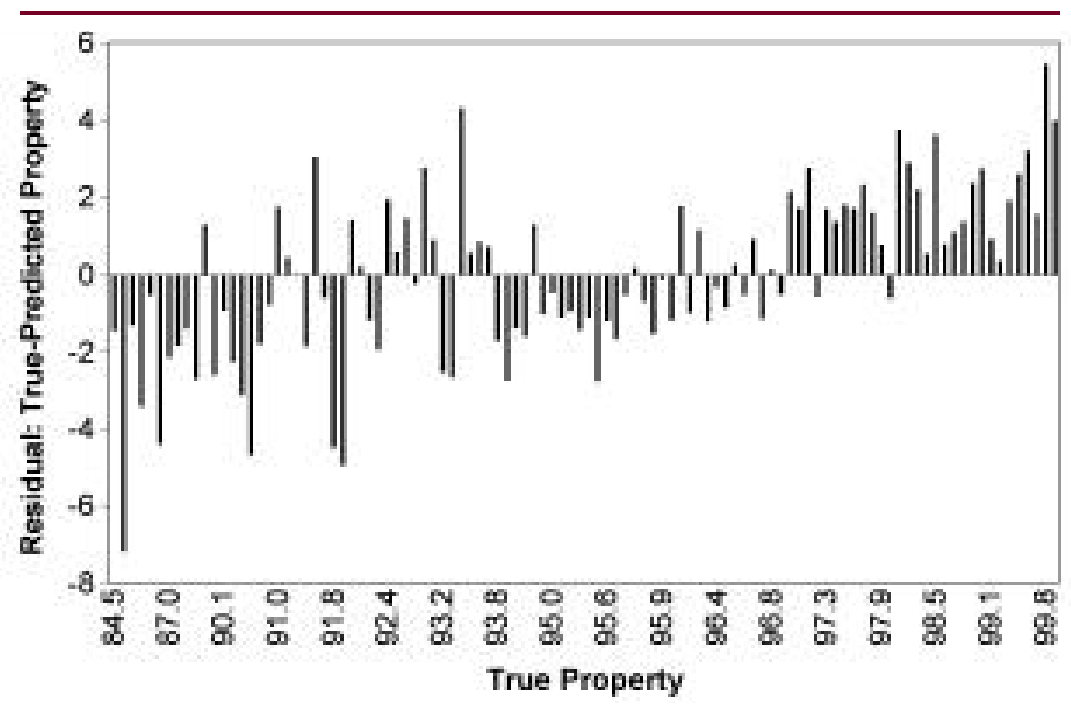

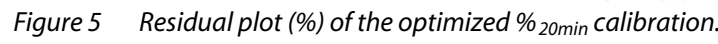

their more homogeneous dissolution process, such models could be a great help in establishing calibrations.

Regular and stability samples both covered only the $85-100 \%$ dissolution range (Figure 4). The trend of the residual plot (Figure 5) was due to the effect of the different storage conditions on the regular and stability tablet parameters. Clearly, therefore, better calibration models could be achieved if the two sample categories were not mixed. Given the cluster behavior, regular samples with a lower extent of dissolution should be used to extend the calibration range. Such samples must be specially produced by varying tablet hardness, the particle size and crystallinity of the active substance, and the crystallinity and amount of breaking excipient. However such a strategy is cost-intensive and timeconsuming during method development, hindering the application of NIR transmission spectroscopy to dissolution. The benefits of routine NIR are fast and non-destructive dissolution analysis. Compared to conventional dissolution testing, a potential decrease in precision could readily be compensated by increasing the required sample number.

In conclusion, this study strongly supports the correlation of NIR transmission spectroscopy to dissolution testing of immediate-release formulations.

\section{References}

[1] Ulmschneider M., Wunenburger A., Pénigault E., Using Near-Infrared Spectroscopy for the Noninvasive Identification of Five Pharmaceutical Active Substances in Sealed Vials, Analusis, 27,854856 (1999)

[2] Ulmschneider M., Barth G., Trenka E., Building Transferable Cluster Calibrations for

relatively small, accounting in particular for the noise level in the $10,600 \mathrm{~cm}-1$ region of the $1 \mathrm{~mm}$ reference spectra (Figure 2), confirmed by the prefered NIR spectra pretreatment normalization. On the other hand, higher scan numbers could warm up the tablets and create spectroscopic artefacts.

Multiple profile shapes were detected in the dissolution process. Factors responsible for the nonhomogeneity were tablet hardness, the particle size and crystallinity of the active substance, the crystallinity and distribution of the breaking excipient, and production by direct compression. Together they made it difficult to apply dissolution models and their parameters to calibrations with the immediate-release formulation. For extended-release formulations, on the other hand, with the Identification of Different Solid Excipients with Near-Infrared Spectroscopy, Pharm.Ind. 62,374-376 (2000)

[3] Ulmschneider M., Barth G., Reder B., Vögel A., Schilling D., Transferable Basic Library for the Identification of Active Substances Using Near-Infrared Spectroscopy, Pharm.Ind.62, 301-304 (2000)

[4] Ulmschneider M., Pénigault E., Direct Identification of Key Intermediates in Containers Using FourierTransform Near-Infrared Spectroscopy Through the Protective Polyethylene Primary Packaging, Analusis, $28,136-140$ (2000)

References ... continued page 28 


\section{Non-destructive Dissolution Testing Correlation ... continued}

[5] Radtke G., Knop K., Lippold B.C., Nahinfrarot (NIR)Spektroskopie: Grundlagen und Anwendung aus pharmazeutischer Sicht, Pharm Ind, 61 (9), 848-857 (1999)

[6] Blanco M., Coello J., Iturriaga H., Maspoch S., de la Pezuela C., Near-Infrared Spectroscopy in the Pharmaceutical Industry, Analyst, 123,135R-150R (1998)

[7] Scheiwe M.-W., Schilling D., Aebi P., Near Infrared Spectroscopy Analysis of Intact Pharmaceutical Diclofenac Coated Tablets in Transmission, Pharm.Ind., 61, 179-183 (1999)

[8] Eustaquio A., Graham P., Jee R.D., Moffatt C., Trafford A.D., Quantification of Paracetamol in Intact Tablets Using Near-Infrared Transmittance Spectroscopy, Analyst, 123, 2303-2306 (1998)

[9] Frickel H., Reich G., Aebi P., Fricker G., Real Thickness of EudragitTM Based Film Coats on Tablet Cores: NonDestructive Analysis with Near-Infrared Transmission Spectroscopy (NIRTRANS), poster presented at AAPS Annual Meeting, San Francisco (1998)

[10] Frickel H., Reich G., Schilling D., Fricker G., How to Make Light Work for Fast Quality Control of EudragitTMBased Film-Coating Formulations on Tablet Cores, poster presented at AAPS Annual Meeting, San Francisco (1998)

[11] Reich G., Frickel H., Use of NIR Transmission Spectroscopy to Determine Physical and Functional Film Coat Properties on Tablets, poster presented at Controlled Release Society, Boston (1999)

[12] Reich G., Use of NIR Transmission Spectroscopy for Nondestructive Determination of Tablet Hardness, Proc. 3rd World Meeting APV/APGI., Berlin (2000)

[13] Kirsch J.D., Drennen J.K., Determination of Film-Coated Tablet Parameters by Near-Infrared Spectroscopy, J. Pharm. Biomed. Anal.13, 1273-1281 (1995)

[14] Morisseau K.M., Rhodes C.T., Near-infrared Spectroscopy as a Nondestructive Alternative to Conventional Tablet Hardness Testing, Pharm. Res. 12, 108-111 (1997)

[15] Guo J.H., Skinner G.W.,Harcum W.W., Malone J.P., Weyer L.G., Application of Near-infrared Spectroscopy in the Pharmaceutical Solid Dosage Form, Drug Dev. Ind. Pharm.,25, 1267-1270 (1999)

[16] Kirsch J.D., Drennen J.K., Nondestructive Tablet Hardness Testing by Near-infrared Spectroscopy: A new and Robust Spectral best-fit Algorithm,J.Pharm. Anal.,19, 351-362 (1999)
[17] Documentation to NIRVIS basic course, Büchi Labortechnik AG, Flawil (1999)

[18] Koch H.P., Die Technik der Dissolutionsbestimmung (Teil 1), Pharm Acta Helv., 59 (4), 98-105 (1984)

[19] Koch H.P., Die Technik der Dissolutionsbestimmung (Teil 2), Pharm. Acta Helv., 59 (5-6), 130-139 (1984)

[20] Koch H.P., Die Technik der Dissolutionsbestimmung (Teil 3), Pharm. Acta Helv., 59 (7), 178-190 (1984)

[21] USP 24 NF19, United States Pharmacopeial Convention,Inc., Rockville, MD (1999)

[22] Pharma Switzerland, Quality Assurance and Quality Control, Analysis Instruction for Benzodiazepine Tablets, F. Hoffmann-La Roche AG, Basel (1999)

[23] Schatz C., Ulmschneider M., Altermatt R., Marrer S., Hollow Shaft Sampling with Fiber Optics, Dissolution Technologies, 7 (1), 20-21 (2000)

[24] Schatz C., Ulmschneider M., Altermatt R., Marrer S., Altorfer H., Manual In Situ Fiber Optic Dissolution Analysis in Quality Control, Dissolution Technologies, 7 (2), 6-13 (2000)

\author{
Correspondence \\ Tanja Kuny \\ Institute of Pharmaceutical Technology \\ University of Basel \\ Klingelbergstr. 50 \\ $\mathrm{CH}-4056$ Basel \\ Switzerland \\ Phone +41-61-267 1505 \\ Fax +41-61-267 1516 \\ tanja.kuny@unibas.ch
}

Dr.Caspar Schatz

F. Hoffmann-La Roche Ltd.

PTDF, Building 9/662

$\mathrm{CH}-4070$ Basel

Switzerland

Phone 41-61-687 1433

Fax +41-61-688 1426

caspar.schatz@roche.com 